\title{
EFFECT OF LIGHT FLASHES ON GROWTH ERFORMANCE, CARCASS CHARACTERISTICS AND CHEMICAL COMPOSITION OF MEAT IN NEW ZEALAND RABBITS
}

\author{
M. F. A. Farghly and M. N. Abd El-Ati \\ Department of Animal and Poultry Production, Faculty of Agriculture, University of \\ Assiut, Egypt
}

\section{SUMMARY}

The present work aimed to study the effect of light flashes on the growth performance, carcass characteristics, gonads, chemical composition and economical efficiency of New Zealand rabbits. Seventy two rabbits aged 8 weeks were randomly divided into three experimental groups (24 rabbit each): The rabbits in control group (C) were exposed to constant light (12 h Light: $12 \mathrm{~h}$ Dark). In the other treated two groups, the $12 \mathrm{~h}$ of daylight period was divided into $6 \mathrm{~h}$ (constant light) and $6 \mathrm{~h}$ (flashes of light) for either $15 \mathrm{~min}$. / h (T1) or $30 \mathrm{~min}$. / h (T2). Exposure of young rabbits to flashes of light affected many of the studied traits and the effects were significant on body weight, weight gain, feed intake, feed conversion, gonads, body temperature, dressed carcass and chemical composition percentages. While, there are insignificant differences in meat protein and carcass cut-up parts percentages. It concluded that the most suitable lighting program for rearing rabbits is the flashes of light (15 min/hour), because it was more economically efficient than continuous or flashes of light (30 $\mathrm{min} / \mathrm{hour}$ ).

Keywords: Rabbits, flashes of light, growth performance, carcass characteristics 